\title{
opinion
}

\section{Molecules of choice?}

\author{
Simon Conway Morris
}

$\mathrm{H}$ ow best to describe evolution? A drunkard's walk; a shambling

billion-year spree punctuated with prat-falls, accompanied by a Beckettian mumbling? Or a sleek greyhound rippling with suppressed energy, racing along the narrow highways of the Darwinian landscape? "Mumble and shuffle" would be the answer of most biologists, but perhaps next time we open our Darwin we should also turn up The Ride of the Valkyries.

When reviewing the evolution of eyes, Russell Fernald hit the nail on the head when he remarked how the opsins have "proven irresistible for use in eyes" [1]. Indeed they have; not only do they belong to the vast family of G-protein-coupled receptors (GPCRs), but it is no accident that, in ears and noses, related transmembrane proteins with the canonical seven helices are also poised to transduce noise and smells into electrical signals and ultimately awareness.

There is a comforting congruity in all this. Just as our eyes register the world through the opsins, in the compound eyes of insects the same proteins wait in attendance. But let us turn to the insect 'nose'. Here, despite a radically different anatomy replete with antennal and maxillary sensilla, the arrangement turns out to be strikingly convergent in terms of operation with the mammalian schnozzle [2], but when we look at the molecular machinery something curious seems to be going on. One component, concentrated in the coeloconic sensilla, is tasked with detecting molecules such as alcohol and ammonia. Here, the machinery depends on the ionotropic glutamate receptors. This appears to be a classic case of co-option because not only are these receptors ancient [3], they also show fascinating links to synaptic receptors [4]. However, the bulk of the olfactory capacity looks to a series of transmembrane proteins. At first glance, complete with their seven helices spanning the sensory membrane, they look reassuringly like the ever-reliable GPCRs. Except they aren't! Blink twice and then notice that these proteins are back to front so that the amino-terminal is cytoplasmic and the carboxy-terminal extracellular. This is completely opposite to the GPCRs [5], but surely it represents a trivial difference? On the contrary. Lurking in the insect 'nose' is a ligand-gated cation channel that at first sight looks practically identical to a GPCR but is completely unrelated [6].

Maybe I am a bear of little brain, but is this not all a little peculiar? Why throw away a perfectly acceptable GPCR — which after all other ecdysozoans such as nematodes use-and install what is effectively a nearperfect mimic? A little trick to keep us on our Darwinian toes? Maybe a clue comes from the choanoflagellates. Central to their life is nitrogen metabolism, but rather oddly the genes they employ have been recruited from algae. "If it ain't broke, don't fix it", except that Aurora Nedelcu and colleagues [7] suggest these imports turned out to be a notch better than the incumbent machinery. Spitfire versus Messerschmitt if you like; both superb aircraft, but the former had the edge.

Perhaps a parallel argument applies to the insects. Their 'noses' might be functionally equivalent to those of mammals but insects live in a different world, zooming through the air at high speed and encountering smells in the form of narrow odour plumes separated by 'clear' air. Rather different from the leisurely inhalations of a large mammal; on the insect scale of things, time is of the essence [8]. This might also explain why there are a variety of transduction cascades, some linked to tried and tested methods but others evidently novel. We should, however, not lose sight of the central point.
Be it in terms of fundamental configurations of olfactory design or the molecular machinery behind it, insects do indeed replay the tape of life, but with end results that are very much the same. With respect to the receptor protein, frankly who cares if it is a GPCR or a ligand-gated ion channel protein? They are completely unrelated, but the far more remarkable fact is that, in terms of transduction, the system evidently has no alternative. The molecule must be a seven-helix transmembrane protein; this is the molecule of choice. Evolution meets design: Darwin and Plato embrace.

Irresistibly, evolution will navigate to this solution. Rest assured that on Threga IXthat charming little planet just to the left of Arcturus-eyes will flicker and noses will swivel beneath an alien sun. We can save ourselves all the fuss of an extremely expensive extraterrestrial excursion. In those alien eyes and noses, we can be quite certain that a seven-helix transmembrane protein will be busy telling its owner that the sunset is red and dinner is almost ready. Gin and tonic anybody?

REFERENCES

1. Fernald RD (2000) Curr Opin Neurobio/ 10: 444-450

2. Ache BW, Young JM (2005) Neuron 48: 417-430

3. Croset V et al (2011) PLoS Genet 6: e1001064

4. Albuin Let al (2011) Neuron 69: 44-60

5. Lundin C et al (2007) FEBS Lett 581: 5601-5604

6. Nakagawa T, Vosshall LB (2009) Curr Opin Neurobio/ 19: 284-292

7. Nedelcu AM, Blakney AJC, Logue KD (2009) J Evol Biol 22: 1882-1894

8. Silbering AF, Benton $\mathrm{R}(2010)$ EMBO Rep 11: 173-179

Simon Conway Morris is a professor in the Department of Earth Sciences, University of Cambridge, UK.

E-mail:sc113@cam.ac.uk

EMBO reports (2012) 13, 281; published online 28 February 2012; doi:10.1038/embor.2012.21 